\title{
Universiteit
}

Leiden

The Netherlands

\section{Genetic influences on thinning of the cerebral cortex during development}

Soelen, I.L.C. van; Brouwer, R.M.; Baal, G.C.M. van; Schnack, H.G.; Peper, J.S.; Collins, D.L.; ... ; Pol, H.E.H.

\section{Citation}

Soelen, I. L. C. van, Brouwer, R. M., Baal, G. C. M. van, Schnack, H. G., Peper, J. S., Collins, D. L., ... Pol, H. E. H. (2012). Genetic influences on thinning of the cerebral cortex during development, 59(4), 3871-80. doi:10.1016/j.neuroimage.2011.11.044

Version: $\quad$ Not Applicable (or Unknown)

License: $\quad$ Leiden University Non-exclusive license

Downloaded from: https://hdl.handle.net/1887/117021

Note: To cite this publication please use the final published version (if applicable). 


\title{
Genetic influences on thinning of the cerebral cortex during development
}

\author{
I.L.C. van Soelen ${ }^{\mathrm{a}, \mathrm{b}}$, R.M. Brouwer ${ }^{\mathrm{a}}$, G.C.M. van Baal ${ }^{\mathrm{a}}$, H.G. Schnack ${ }^{\mathrm{a}}$, J.S. Peper ${ }^{\text {a,c }}$, D.L. Collins ${ }^{\text {d }}$, A.C. Evans ${ }^{\mathrm{d}}$, \\ R.S. Kahn ${ }^{a}$, D.I. Boomsma ${ }^{\text {b, } *, 1}$, H.E. Hulshoff Pol ${ }^{\mathrm{a}, * *, 1}$ \\ a Rudolf Magnus Institute of Neuroscience, Department of Psychiatry, University Medical Center Utrecht, Postbus 85500, 3508 GA Utrecht, The Netherlands \\ ${ }^{\mathrm{b}}$ Department of Biological Psychology, VU University Amsterdam, van der Boechorststraat 1, 1081 BT Amsterdam, The Netherlands \\ c Institute of Psychology, Brain and Development Laboratory, Leiden University, Wassenaarseweg 52, 2333 AK Leiden, The Netherlands \\ ${ }^{d}$ McConnell Brain Imaging Centre, Montreal Neurological Institute, McGill University, Montreal, QC, Canada H3A 2B4
}

\section{A R T I C L E I N F O}

\section{Article history:}

Received 30 May 2011

Revised 14 November 2011

Accepted 15 November 2011

Available online 1 December 2011

\section{Keywords:}

Cortical thickness

Heritability

Longitudinal twin study

Neurodevelopment

Structural MRI

\begin{abstract}
A B S T R A C T
During development from childhood to adulthood the human brain undergoes considerable thinning of the cerebral cortex. Whether developmental cortical thinning is influenced by genes and if independent genetic factors influence different parts of the cortex is not known. Magnetic resonance brain imaging was done in twins at age $9(\mathrm{~N}=190)$ and again at age $12(\mathrm{~N}=125 ; 113$ repeated measures $)$ to assess genetic influences on changes in cortical thinning. We find considerable thinning of the cortex between over this three year interval (on average $0.05 \mathrm{~mm} ; 1.5 \%$ ), particularly in the frontal poles, and orbitofrontal, paracentral, and occipital cortices. Cortical thinning was highly heritable at age 9 and age 12, and the degree of genetic influence differed for the various areas of the brain. One genetic factor affected left inferior frontal (Broca's area), and left parietal (Wernicke's area) thinning; a second factor influenced left anterior paracentral (sensory-motor) thinning. Two factors influenced cortical thinning in the frontal poles: one of decreasing influence over time, and another independent genetic factor emerging at age 12 in left and right frontal poles. Thus, thinning of the cerebral cortex is heritable in children between the ages 9 and 12. Furthermore, different genetic factors are responsible for variation in cortical thickness at ages 9 and 12, with independent genetic factors acting on cortical thickness across time and between various brain areas during childhood brain development.
\end{abstract}

(c) 2011 Elsevier Inc. All rights reserved.

\section{Introduction}

Our understanding of human brain development has expanded exponentially over the past decade. The non-invasive nature of magnetic resonance imaging (MRI) has allowed measurements of changes in brain structure in healthy children and adults. Using MRI, it has become evident that the human cerebral cortex undergoes considerable developmental changes during childhood and adolescence. After extensive growth of the brain in gray and white matter volume during early childhood, gray matter volume starts to decrease around puberty (Giedd et al., 1999). This is due to a considerable thinning of the cortex that occurs in children continuing throughout adolescence (Gogtay et al., 2004; Sowell et al., 2002), and beyond in adulthood (Brans et al., 2010). Timing of cortical thinning differs between areas. During development in childhood, thinning of primary cortical areas precedes that of secondary

\footnotetext{
Abbreviations: DZ, dizygotic; FDR, False Discovery Rate; MZ, monozygotic.

* Correspondence to: D.I. Boomsma, Department of Biological Psychology, VU University, Van der Boehorststraat 1, 1081 BT, Amsterdam, The Netherlands.

** Correspondence to: H.E. Hulshoff Pol, Department of Psychiatry, A01.126, University Medical Center Utrecht, Heidelberglaan 100, 3584 CX Utrecht, The Netherlands.

E-mail addresses: di.boomsma@vu.nl (D.I. Boomsma), h.e.hulshoff@umcutrecht.nl (H.E. Hulshoff Pol).

${ }^{1}$ Equal last author(s)
}

cortical areas (Gogtay et al., 2004). Currently it is not known to what extent genetic and environmental influences drive these brain changes during the crucial period of transition from childhood to adulthood. Twin studies are widely used to quantify to what extent genetic and environmental factors influence individual differences in observed traits, by comparing the similarities within MZ and DZ twin pairs on a specific trait. The proportion of total variance that can be attributed to genetic variance is termed heritability. Variation in global brain volumes is explained to a large extent by genetic influences (around 70-80\%) in adults (Baare et al., 2001; Peper et al., 2007; Kremen et al., 2010), and in children and adolescents (Wallace et al., 2006; Schmitt et al., 2007a, 2007b; Peper et al., 2009; Yoon et al., 2010; van Soelen et al., 2011a). Moderate to high heritability for local cortical thickness throughout the cortex was previously reported in children (Lenroot et al., 2009; Yoon et al., 2010), adults (Brans et al., 2010), and in middle-aged men (Panizzon et al., 2009; Kremen et al., 2010). Thus, brain volume and cortical thickness are heritable traits in children and heritability estimates have been suggested to increase with age (Lenroot et al., 2009; Wallace et al., 2006). Interestingly, genetic influences on cortical changes were independent of those implicated in absolute cortical thickness (Brans et al., 2010). However, whether one single genetic factor influences cortical thinning during adolescence, or in contrast whether multiple (independent) genetic factors affect different brain areas is not known. We hypothesized that 1) cortical thinning between ages 
9 and 12 is heritable; 2) during brain development heritability of cortical thickness increases. Considering the dynamical changes in cortical thickness in this period, we hypothesize that new genetic variance acting on cortical thickness emerges between 9 and 12 years of age; 3 ) genetic factors exert their influence on the development of the cerebral cortex in a region-specific manner.

\section{Material and methods}

\section{Subjects}

Twin pairs were recruited from the Netherlands Twin Register (NTR; Boomsma et al., 2006) around their 9th birthday (van Leeuwen et al., 2008; Peper et al., 2008). Exclusion criteria for the participation of the children included having a pacemaker, any metal materials in the head (including dental braces), the chronic use of medication, a known major medical or psychiatric history, and participation in special education. Parents and children gave written informed consent to participate in the study. The study was approved by the Central Committee on Research involving Human Subjects (CCMO) of the Netherlands and experiments were in accordance with the Declaration of Helsinki.

At age 9 a total of 208 twins completed the scan protocol (coming from 106 families). Due to movement artefacts, $8 \mathrm{MZ}$ and $10 \mathrm{DZ}$ twins could not be included for image processing of the scans. As a result, a total of 190 twins were included in the analyses at age 9 , consisting of $82 \mathrm{MZ}$ twins (38 complete twin pairs), 75 same-sex DZ twins (32 complete twin pairs), and 33 opposite-sex DZ twins (14 complete twin pairs). Mean age (s.d.) of twins at baseline was 9.2 (0.1) with a range from 9.0 up to 9.7 years old (Table 1 ).

Nearly $80 \%$ of the families returned for the follow-up at age 12 , and 136 twins completed the scan procedures. The lower number of children who participated in scanning at follow-up was mainly due to the increase in prevalence of metallic braces at age 12 , which is common around this age. After exclusion due to movement artefacts, 125 scans at age 12 (excluding $7 \mathrm{MZ}$ and $4 \mathrm{DZ}$ twins) were included in the analyses. As a result, there were MRI data for $56 \mathrm{MZ}$ twins ( 23 complete twin pairs), 45 same-sex DZ twins ( 18 complete pairs), and 24 opposite-sex twins (10 complete pairs) at the second assessment. Mean age (s.d.) at follow-up was 12.1 (0.3) years, ranging from 11.7 up to 13.1 years old. For 113 children there were MRI data at both baseline and follow-up (42 complete twin pairs). Mean interval time was 2.9 years $(0.2)$, and the range was 2.5 up to 3.5 years. Zygosity of the same-sex twin pairs was determined based on DNA polymorphisms. Handedness was determined based on Edinburgh Handedness Inventory (Oldfield, 1971). Mean (s.d.) full scale IQ of the complete sample was 99.9 (13.5) at age 9, and

Table 1

Sample descriptives of monozygotic (MZ) and dizygotic (DZ) same sex and opposite sex twin pairs at age 9 , age 12 , and of the twins that were included with complete datasets at both measurements.

\begin{tabular}{|c|c|c|c|}
\hline & Baseline & Follow-up & $\begin{array}{l}\text { Both } \\
\text { measurements }\end{array}$ \\
\hline $\begin{array}{l}\text { Total number of twins } \\
\text { (male/female) }\end{array}$ & $190(91 / 99)$ & $125(66 / 59)$ & $113(60 / 53)$ \\
\hline $\begin{array}{l}\text { Mean age at scanning in years } \\
(\text { s.d.) }\end{array}$ & $9.2(0.1)$ & $12.1(0.3)$ & $2.9(0.2)^{\mathrm{a}}$ \\
\hline Handedness (right/non-right) & $158 / 32$ & $105 / 20$ & $95 / 18$ \\
\hline $\begin{array}{l}\text { MZ twins } \\
\quad \text { (number of complete pairs) }\end{array}$ & $82(38)$ & $56(23)$ & $51(25)$ \\
\hline $\begin{array}{l}\text { DZ same-sex twins } \\
\text { ( } N \text { complete pairs })\end{array}$ & $75(32)$ & $45(18)$ & 40 (19) \\
\hline $\begin{array}{l}\text { DZ opposite-sex twins } \\
\text { ( } N \text { complete pairs })\end{array}$ & $33(14)$ & $24(10)$ & $22(11)$ \\
\hline
\end{tabular}

a Mean time interval in years is given between scans at baseline and follow-up.
100.3 (14.1) at 12, illustrating that the sample was representative of the general population (van Soelen et al., 2011b).

\section{Image acquisition}

To limit possible effects of scanner instability over time, the same scanner parameters as well image processing procedures were applied at both measurements. All structural magnetic resonance imaging (MRI) was performed on a 1.5-T Philips Achieva scanner at both ages 9 and 12. Scanning and the subsequent image processing took place at the University Medical Center Utrecht, The Netherlands. All children underwent a practicing session in a dummy scanner in advance to get familiarized with the scan procedure, small space and the sounds of the MRI machine (Durston et al., 2009). At both measurements image-sequences of the whole head were acquired, including a short scout scan for immediate verification of optimal head positioning, and a clinical scan that was used for neurodiagnostic evaluation. Threedimensional T1-weighted coronal spoiled-gradient echo scan of the whole head $(256 \times 256$ matrix, $\mathrm{TE}=4.6 \mathrm{~ms}, \mathrm{TR}=30 \mathrm{~ms}$, flip angle $=$ $30^{\circ}, 160-180$ contiguous slices; $1 \times 1 \times 1.2 \mathrm{~mm}^{3}$ voxels, Field-of-View $=$ $256 \mathrm{~mm} / 70 \%$ ) was acquired for volumetric analysis. Additionally, a DTIB0 (Diffusion Tensor Imaging; transverse; 15-64 directions; SENSE factor 2.5, b-factor 1000 ; flip angle $90^{\circ} ; 60$ slices of $2.5 \mathrm{~mm}$; slice gap $0 ; 128 \times 96$ acquisition matrix; FOV $240 \mathrm{~mm}$; TE $=60-88 \mathrm{~ms}$ ) and a MTR (Magnetic Transfer Ratio; transverse; MTC frequency offset $1100 \mathrm{~Hz} ; 60$ slices of $2.5 \mathrm{~mm}$; slice gap 0; $128 \times 96$ acquisition matrix; FOV $240 \mathrm{~mm}$; flip angle $8^{\circ} ; \mathrm{TE}=4.5 \mathrm{~ms}$; TR $=37.5 \mathrm{~ms}$ ) were acquired at both ages 9 and 12 (as previously described by Peper et al., 2008). At follow-up only, a T2-weighted image was added to the scan protocol (transverse, parallel imaging, SENSE factor 2 , TE $1=15 \mathrm{~ms}$, TE2 $=80 \mathrm{~ms}$, TR $=6000 \mathrm{~ms}$, flip angle $=90^{\circ}, 120$ slices of $1.6 \mathrm{~mm}$, slicegap $0.0 \mathrm{~mm}$, Field-ofview $=250 \mathrm{~mm} / 80 \%$ ) for optimization of image processing as described below.

\section{Image processing}

Scans were put into Talairach frame (no scaling), and corrected for inhomogeneities in the magnetic field (Sled et al., 1998). Quantitative assessment of intracranial volume (IC) at age 9 was based on the DTIBT0 and MTR images as described earlier (Peper et al., 2008). For the segmentation of IC volume at age 12, the T1-weighted image was individually warped non-linearly to their T1-weighted image at age 9 (when available). The IC segments at age 12 were created from the IC segments at age 9 using this nonlinearly transformation. When no IC segment was available at age 9, the T2-weighted image at age 12 was used to create an IC segment $(\mathrm{N}=10)$. For one participant, the same method as described for 9 year old assessment was used (DTI-BT0 and MTR) to create an IC segment for the follow-up at age 12. All IC segments at age 9 and age 12 were checked and edited where necessary. Cerebral spinal fluid, gray and white matter were segmented using a partial volume segmentation method incorporating a non-uniform partial volume distribution (Brouwer et al., 2010).

Cortical thickness was computed using a custom version of the CLASP algorithm, designed at the McConnell Brain Imaging Centre, Montreal (Kim et al., 2005; Lerch et al., 2008), which started from the gray and white matter segments created by our own algorithm as described above (Brans et al., 2010). A 3D surface was fitted to the white matter/gray matter interface, which created the inner surface of the cortex and then expanded out to fit the gray matter/cerebrospinal fluid interface, thereby creating the outer cortical surface (Kim et al., 2005). Cortical thickness was estimated by taking the distance between the two surfaces on each vertex (40962 vertices per hemisphere), followed by smoothing across the surface using a $20 \mathrm{~mm}$ full-width at half-maximum (FWHM) surface-based blurring kernel. This method of blurring simultaneously improves the chances of detecting population differences and also follows 
the curvature of the surface to preserve any anatomical boundaries within the surface. The surfaces of the subjects were registered to an average surface (International Consortium for Brain Mapping; Lyttelton et al., 2007), allowing comparison of cortical thickness locally between and within subjects over time. In addition, mean cortical thickness was calculated for each person at both ages 9 and 12 (no smoothing).

\section{Study design}

A longitudinal twin design was applied. A larger correlation between members of MZ pairs compared to DZ pairs indicates genetic influences on a certain trait, such as, cortical thickness. The longitudinal follow-up of twins allows for estimation of cross-twin/cross-time correlations, such as cortical thickness at age 9 in one twin with cortical thickness at age 12 in the co-twin. Larger MZ cross-correlations than DZ crosscorrelations indicate that there is an association between genetic factors at ages 9 and 12. If MZ cross-correlations are not larger than DZ crosscorrelations there is no such overlap in genetic factors over time. Similarly, cross-twin/cross-area correlations can elucidate whether different genetic factors are implicated across the cerebral cortex.

\section{Genetic modeling}

Because MZ twins share almost all their genetic material, and DZ twins share approximately half of their segregating genes with each other, twin data allow for decomposition of the observed (or phenotypic) variance into genetic and environmental components. Additive genetic influences $(A)$ represent effects on the phenotype of multiple alleles at different loci across the genome that act additively. Common environmental influences $(\mathrm{C}$ ) represent sources of variance that twins from the same family share. Unique environmental influences (E) are not shared by family members (Boomsma et al., 2002; Falconer and Mackay, 1996). Within a structural equation modeling approach, A, C, and $\mathrm{E}$ can be considered to be latent factors, standardized to have unit variance. Thus, the term of genetic factor represents the combined effects of multiple genes that act on the phenotype. By definition, the correlation between the latent genetic factors of co-twins is 1.0 for MZ and 0.5 for DZ pairs. The correlation between common environmental influences is 1.0 for both $\mathrm{MZ}$ and $\mathrm{DZ}$ pairs. Unique environmental influences (E) are by definition uncorrelated in all twin pairs, and also include measurement error. This correlation structure among latent factors identifies the model.

\section{Longitudinal genetic modeling}

A longitudinal structural equation model was fitted to the data to estimate the influences (specified as path coefficients) of A, C and $\mathrm{E}$ on the phenotype at ages 9 and 12 . Genetic factors at age 9 can have the same influence over time, or may become more or less important with increasing age. Because common environmental influences were non-significant for all brain measures, we limit the description of the model to an AE model (see Fig. 1).

The path coefficient $a_{11}$ quantifies the effect of genetic influences on the phenotype at age 9 , and $a_{21}$ quantifies the effect of these same genetic influences at age 12. The genetic covariance between ages 9 and 12 equals $a_{11}{ }^{*} a_{21}$. Finally, $a_{22}$ quantifies the effect of genetic variance acting only at age 12 . In a similar way $e_{11}, e_{21}$, and $e_{22}$ are defined. The variance at age 9 is $\left(a_{11}\right)^{2}+\left(e_{11}\right)^{2}$. The total variance at age 12 equals $\left(a_{21}\right)^{2}+\left(a_{22}\right)^{2}+\left(e_{21}\right)^{2}+\left(e_{22}\right)^{2}$. Heritability is the proportion of the total variance that can be attributed to genetic variance. Hence, heritability at age 9 is $a_{11}^{2} /\left(a_{11}^{2}+e_{11}^{2}\right)$, and heritability at age 12 is $\left(a_{21}^{2}+a_{22}^{2}\right)$ / $\left(a_{21}^{2}+a_{22}^{2}+e_{21}^{2}+e_{22}^{2}\right)$.

The longitudinal model (see Fig. 1) also specifies a change score to gain insight into the contribution of genetic variance on individual differences in developmental change from ages 9 to 12. The total variance on the change score is calculated by: Variance $($ age $12-$ age 9) $=$ Variance $_{(\text {age } 9)}+$ Variance $_{(\text {age } 12)}-2 *\left(\right.$ Covariance $\left._{(\text {age } 12 \text {, age } 9)}\right)$. Following path tracing rules in the longitudinal path diagram, the contribution of genetic variance on developmental change is calculated as $a_{11}^{2}+a_{21}^{2}+a_{22}^{2}-2 *\left(a_{11} * a_{21}\right)$. Simplified this gives: $\left(a_{21}-a_{11}\right)^{2}+$ $a_{22}^{2}$, where the first part represents the gradual change in effect size defined by between paths $a_{11}$ and $a_{21}$ of the genetic factor that is present at ages 9 and 12, and the second part represents the contribution of specific genetic influence at age 12 on total variance of cortical change.

Thus, we can observe regions where at age 12 new genetic factors influence cortical thickness. In this paper we refer to genetic influences that are expressed at age 12 but not at age 9 as genetic innovations (i.e., $a_{22}>0$ ). Genetic influences that overlap between ages 9 and 12 , are referred to as stable genetic factors. These stable genetic factors can become more important (amplification) or less important (attenuation) as children grow older. Amplification of genetic influences is indicated by increases in path coefficients $a_{21}$ compared to $a_{11}$. Attenuation of genetic influences is present if $a_{21}<a_{11}$. Please note that only when $a_{22}$ is not equal to zero or when $a_{21}$ differs from $a_{11}$, non-zero heritability estimates for change scores will be observed. The relative importance of stable genetic influences is referred to as the heritability due to $A_{1}$. Heritability is defined as the genetic variance divided by the total variance of the phenotype. Hence there can be genetic amplification (when genetic variance at age 12 due to $A_{1}$ is larger than at age 9 ) and at the same time decreasing heritability (when the genetic variance is divided by a larger total variance because there also is genetic innovation and/or increased nongenetic variance).

\section{Statistical analyses}

For descriptive purposes, changes in cortical thickness across time were calculated in millimeter ( $\mathrm{mm}$ ) for all participants with longitudinal data. Changes in local cortical thickness were calculated vertexby-vertex. The changes in cortical thickness between ages 9 and 12 were tested for significance by a $t$-test, while adjusting the degree of freedom for familial dependence. These analyses were corrected for sex, handedness and duration of the scan-interval.

Genetic analyses were carried out by structural equation modeling (SEM) as implemented in the software package Mx (Neale et al., 2006). Parameters were estimated by maximum likelihood. This was done for each vertex of cortical thickness, while data were corrected for sex, age at scanning, and handedness effects at both time points. All available data, including data from incomplete twin pairs or twins who participated once, were analyzed.

The minimal requirements to have heritability of change in cortical thickness include variation in cortical thinning, and genetic influences on cortical thickness that are present at either ages 9 or 12 (or both; see Fig. 1). Therefore, regions were selected in advance of the longitudinal genetic modeling based on (i) the presence of cortical thinning over time and (ii) the presence of genetic influences at 9 and/or at 12 years of age (assessed by univariate genetic modeling). For these selection criteria correction for multiple comparisons was done according to the False Discovery Rate (FDR) at a level of 0.05 (Genovese et al., 2002).

To gain insight into the genetic model for cortical thinning that best described the data we first tested for the presence of genetic innovation at age 12 by constraining the parameter of interest at zero (e.g., $a_{22}$ ) and compared the model-fit with the model where the parameter was freely estimated. Second, gradual differences in effect size over time of stable genetic influences acting at ages 9 and 12 were tested by constraining the paths $a_{11}$ and $a_{21}$ to be equal, and compare the model-fit again with the model where these parameters were freely estimated. For the regions where we obtained evidence of the presence of genetic innovation (i.e., $a_{22}>0$ ), this second test was 


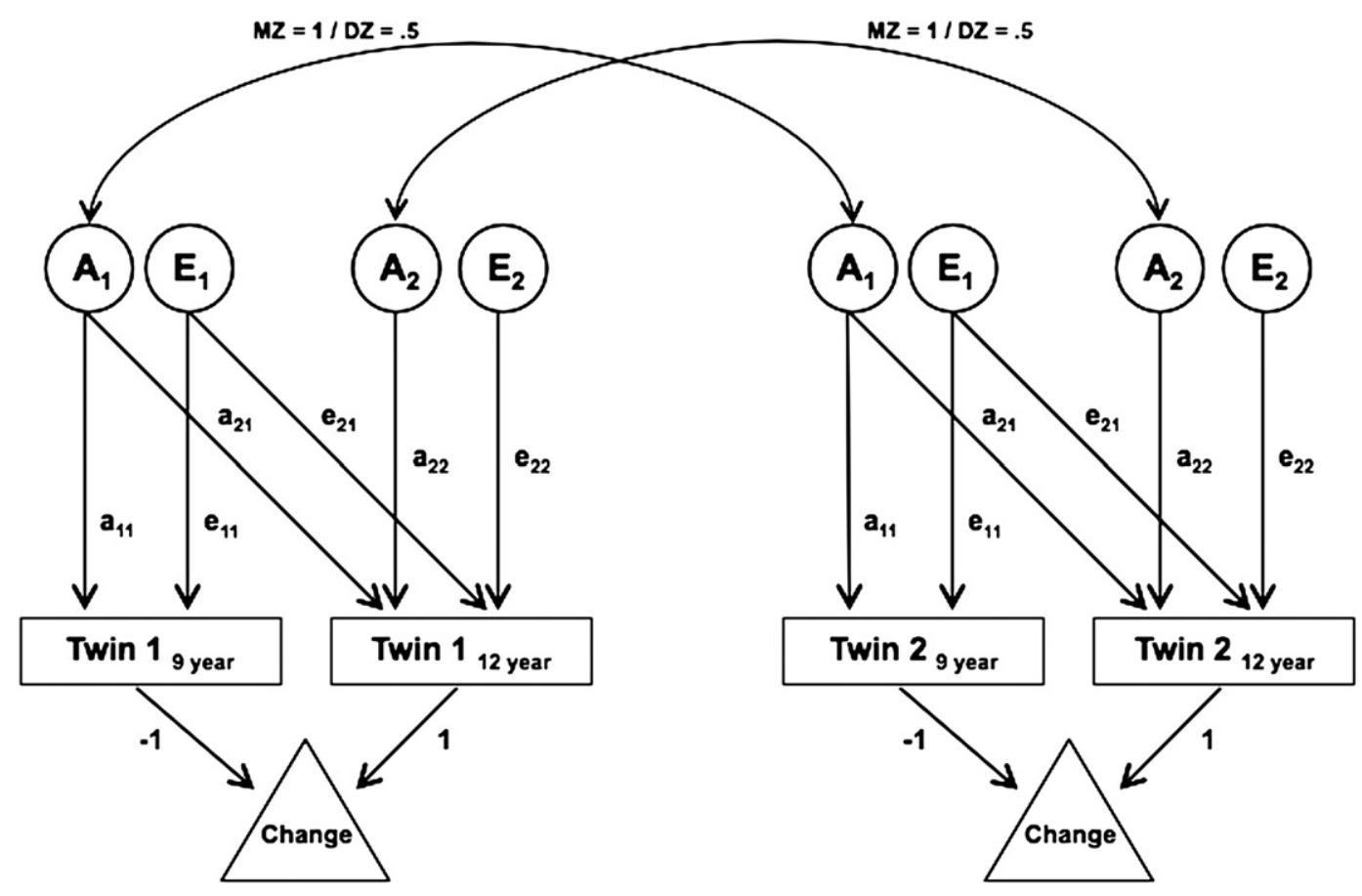

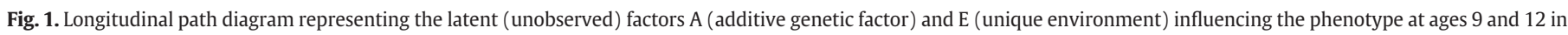

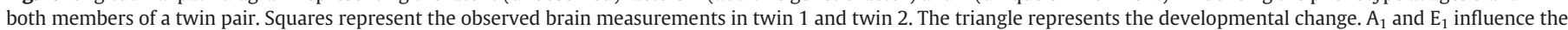

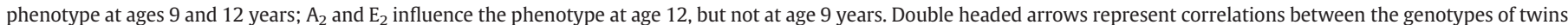

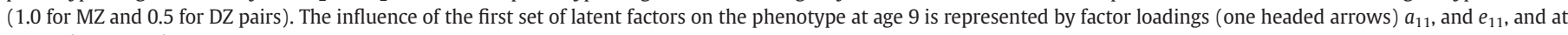
age 12 by $a_{21}$, and $e_{21}$.

carried out with $a_{22}$ as a free parameter. For the regions where we did not find genetic innovation, we tested if there were differences in the effect sizes of stable genetic influences acting at ages 9 and 12 with $a_{22}=0$.

Model comparisons were done by likelihood ratio tests. These tests compare the differences between $-2 * \log$ likelihood of the full model with that of a restricted nested model against the corresponding degrees of freedom (df). This difference has a chi-squared distribution. When a variance component was fixed at zero, a one-tailedtest was used (Dominicus et al., 2006).

\section{Multivariate genetic modeling for selected regions}

To explore whether genetic factors acting on cortical change showed an overlap between regions, we performed additional exploratory multivariate analysis on the change scores. Multivariate genetic modeling of change scores was based on cross-twin/cross-trait correlations instead of cross-twin/cross-time correlations as described above. The genetic covariance (or the standardized genetic covariance $\left(r_{g}\right)$ ) hence describes the extent of overlap between genetic factors acting on cortical changes in different regions.

Within the regions where genetic innovation was observed (i.e., $\mathrm{a}_{22}>0$ ), single vertices were selected based on the highest value in the significant clusters $\left(\chi^{2}>2.71\right.$; see section Statistical analyses). Within the regions where the influence of stable genetic factors changed between ages 9 and 12, single vertices were also selected based on the highest value in the significant clusters $\left(\chi^{2}>3.84\right.$; see section Statistical analyses). Within the multivariate models genetic covariance between the selected vertices was tested for significance by constraining the genetic covariance between the vertices across regions at zero. If this model fitted worse, we concluded that genetic factors acting on cortical change were shared between these regions.

\section{Results}

\section{Univariate genetic modeling}

Genetic influences contributed significantly to mean cortical thickness. The heritability of mean cortical thickness was $65 \%(\mathrm{p}<0.01)$ at age 9 , and $82 \%(p<0.01)$ at age 12 . Estimates of heritability for local cortical thickness at both ages 9 and 12 mapped throughout the cortex can be found in Figs. 2 and 3.

At age 9 , several areas of the cortex showed significant heritability estimates with a mean heritability of $21 \%$ (ranging from $0 \%$ up to $78 \%$ ) in the left and a mean heritability of $21 \%$ (ranging from $0 \%$ up to $73 \%$ ) in the right hemisphere. Areas that showed significant contributions of genetic influences at age 9 were located bilaterally in frontal, midsagittal frontal, temporal and inferior parietal areas, inferior and medial insula, cingulate, the anterior paracentral lobule, lingual gyrus, precuneus, cuneus, calcarine sulcus, lateral occipital areas, and left parahippocampal gyrus (FDR corrected, $\mathrm{p}<0.05$; see Fig. 2 ).

At age 12 , the mean heritability estimates for local cortical thickness were $22 \%$ (from $0 \%$ up to $88 \%$ ) and $23 \%$ (from $0 \%$ up to $91 \%$ ) in left and right hemispheres, respectively. Significant heritability estimates at age 12 were located bilaterally in the precuneus, left inferior, and midsagittal superior frontal areas, left anterior paracentral lobule, left inferior temporal, and left lateral occipital gyri. In the right hemisphere, significant heritability estimates were found in the superior frontal, inferior parietal, inferior temporal, and cuneus (FDR corrected, $\mathrm{p}<0.05$; see Fig. 3 ). The percentage overlap between vertices with significant heritability at age 9 that were also significantly heritable at age 12 was $18.6 \%$.

Because heritability is defined as a proportion of the total variance, changes in the unstandardized values of the genetic and environmental components and the total variances were evaluated between ages 9 and 12. The total variance showed an overall decrease across the 


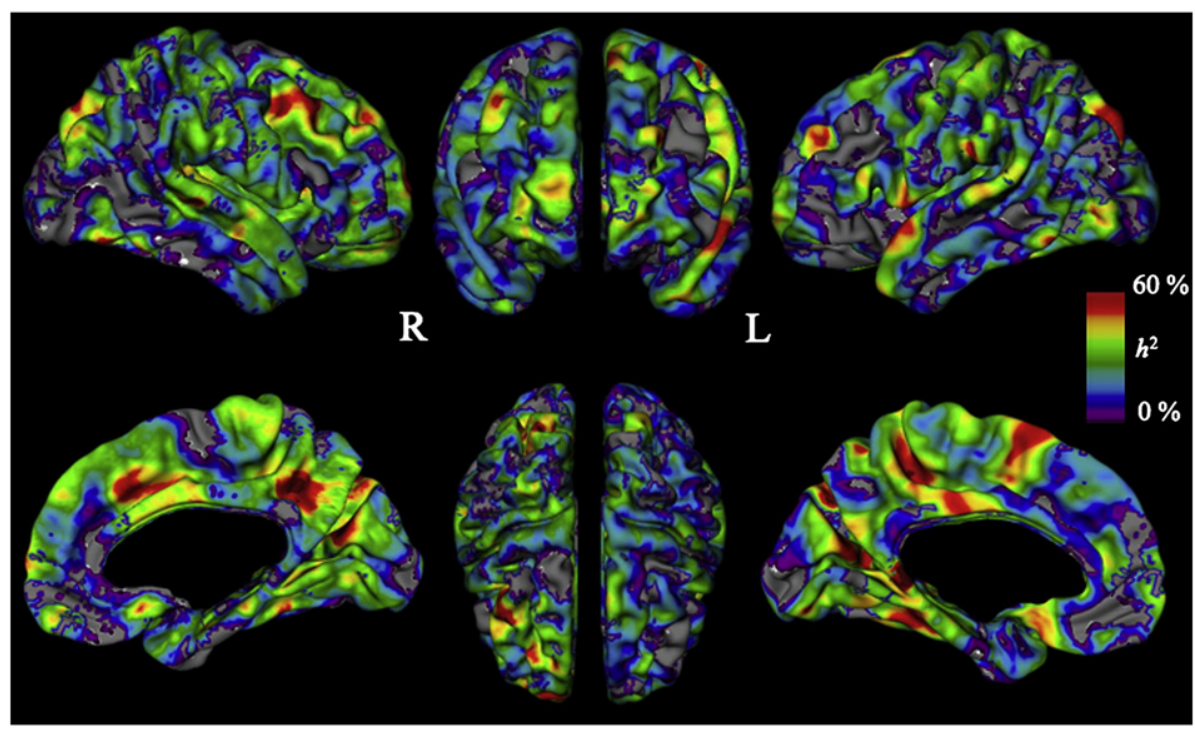

Fig. 2. Heritability estimates $\left(h^{2}\right)$ of local cortical thickness at age 9 . Heritability ranged up to a maximum of $78 \%$ at age 9 .

cortex between the two measurement points. This was mostly due to decreased unique environmental influences. It should be noted that regions of increased and decreased heritability coincide with an increase or decrease of unstandardized genetic variance.

\section{Developmental changes}

A significant decrease in mean cortical thickness of $0.05 \mathrm{~mm}$ $(\mathrm{p}<0.01)$ was observed between ages 9 and 12 . No significant heritability of mean cortical thinning was found. Changes in local cortical thickness between 9 and 12 years were calculated for each vertex separately and significant cortical thinning was observed throughout the cortex (FDR corrected, $\mathrm{p}<0.05$ ). The amount of thinning was widely distributed over the different regions, and was most pronounced in the frontal pole, parietal and lateral occipital cortices (Fig. 4). The amount of cortical thinning did not differ significantly between girls and boys. There were no areas with significant cortical thickening.

\section{Heritability of cortical thinning}

For cortical areas where significant cortical thinning and significant genetic influences on cortical thickness at ages 9 and/or 12 were found (all based on FDR corrected data, leaving 7841 vertices in the left hemisphere, and 10173 vertices in the right hemisphere, see Fig. 6 for areas that were included), genetic influences on individual differences in cortical thinning were explored in the longitudinal path model as depicted in Fig. 1. Heritability estimates of cortical thinning locally were predominantly found in superior and middle frontal areas, superior temporal areas, cingulate, sensorimotor cortices, primary visual and lateral occipital cortices (Fig. 5).

First, the presence of significant genetic innovation at age 12 was evaluated. Areas with genetic innovation were located in bilateral superior frontal areas, parieto-occipital sulcus, right medial frontal areas, and anterior cingulate, left superior temporal, and lateral occipital areas $\left(\chi^{2}>2.71\right.$, one-tailed test, $\mathrm{p}<0.05$; see Fig. 6 , Table 2$)$.

Second, in the regions where variance in cortical thickness between ages 9 and 12 could be explained by stable genetic influences (i.e., no

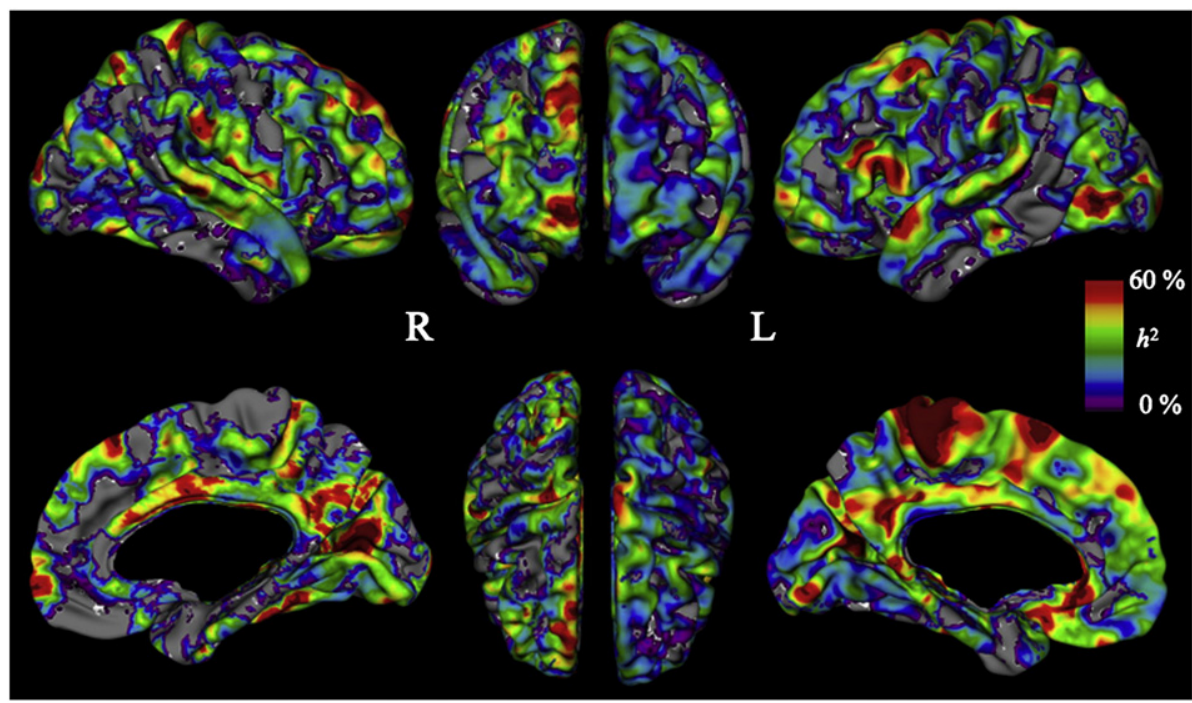

Fig. 3. Heritability estimates $\left(h^{2}\right)$ of local cortical thickness at age 12 . Heritability ranged up to a maximum $91 \%$ at age 12 . 


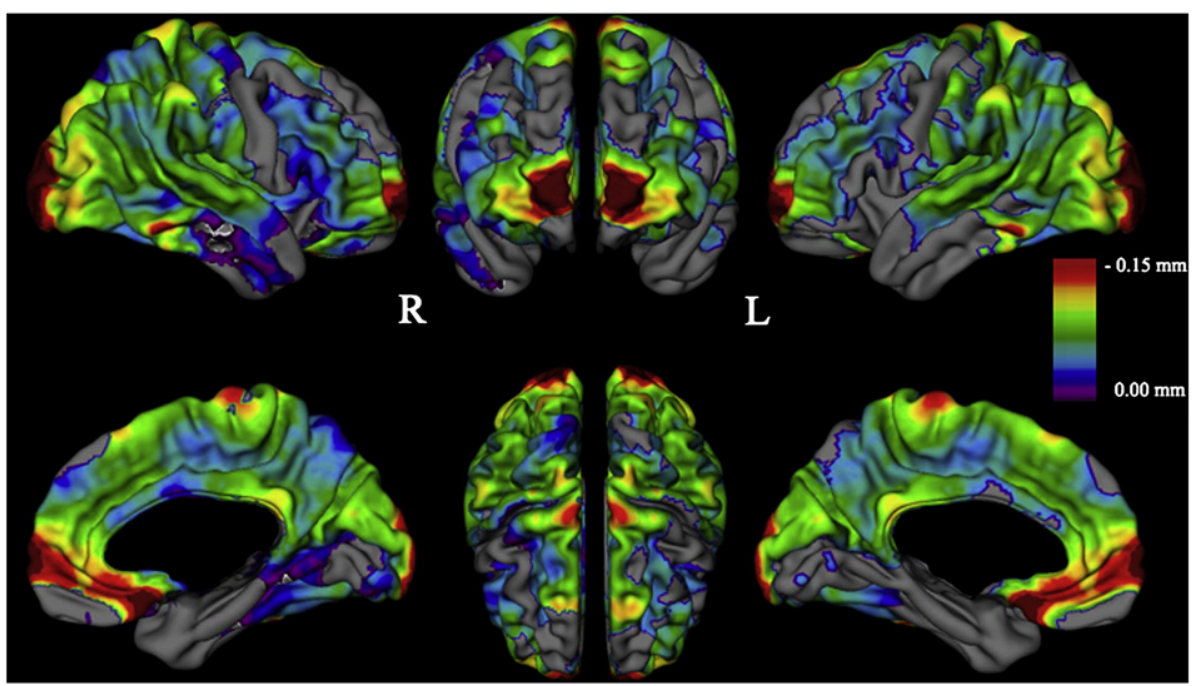

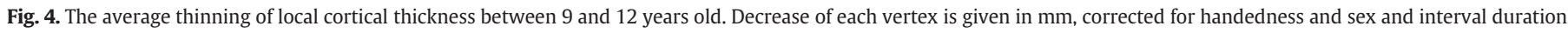

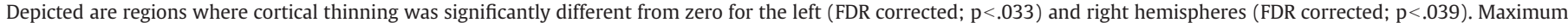
thinning was $0.24 \mathrm{~mm}$ in the occipital cortex.

genetic innovation at age 12), we tested whether stable genetic influences across time had an increasing or decreasing influence between ages 9 and 12. Significant increases in effect sizes of stable genetic influences were found at the right central sulcus, calcarine sulcus, inferior isthmus, and left anterior paracentral lobule, rostral cingulate, inferior parietal lobule, and inferior frontal gyrus ( $\chi^{2}>3.84$, two-tailed test, $\mathrm{p}<0.05$; Fig. 6 , Table $3 \mathrm{~A}$ ). Areas where stable genetic influences significantly decreased in magnitude were located in bilaterally inferior parietal, right inferior parietal, medial and superior pre-frontal, left anterior cingulate sulcus, frontal, and inferior temporal areas (Fig. 6, Table 3B).

\section{Multivariate genetic modeling}

The overlap of genetic factors acting on cortical thinning across different regions was explored with multivariate models using the change scores of single vertices. Phenotypic and genetic correlations between the selected regions on cortical thickness change scores are given in Table 4. For regions with genetic innovation, cortical changes were genetically correlated between frontal regions bilaterally $\left(r_{g}=0.83\right)$. For regions where stable genetic influences of increasing magnitude were observed, the genetic influences acting on cortical change in left inferior parietal showed a complete overlap with the genetic influences acting on cortical change in left inferior frontal region $\left(r_{g}=1.00\right)$. These genetic influences did not overlap with the genetic influences acting on cortical changes in left anterior paracentral lobule. In selected regions with stable genetic influences that decreased in importance no genetic overlap was found.

Two vertices located anatomically close to each other in the right frontal region, were chosen to study in more detail (see Fig. 7). For one of these cortical regions, stable genetic influences were found to act on cortical thickness at both points in time $\left(r_{g}=1.00\right)$, and this genetic factor decreased in importance over time (Fig. 7; vertex 1). For a region close to vertex 1, genetic innovation was found (Fig. 7; vertex 2). The common genetic factor at vertex 1 showed a significant overlap with the genetic factor at age 9 of vertex $2\left(r_{g}=0.80\right)$, and no significant overlap with the genetic factor at age 12 of vertex 2 .

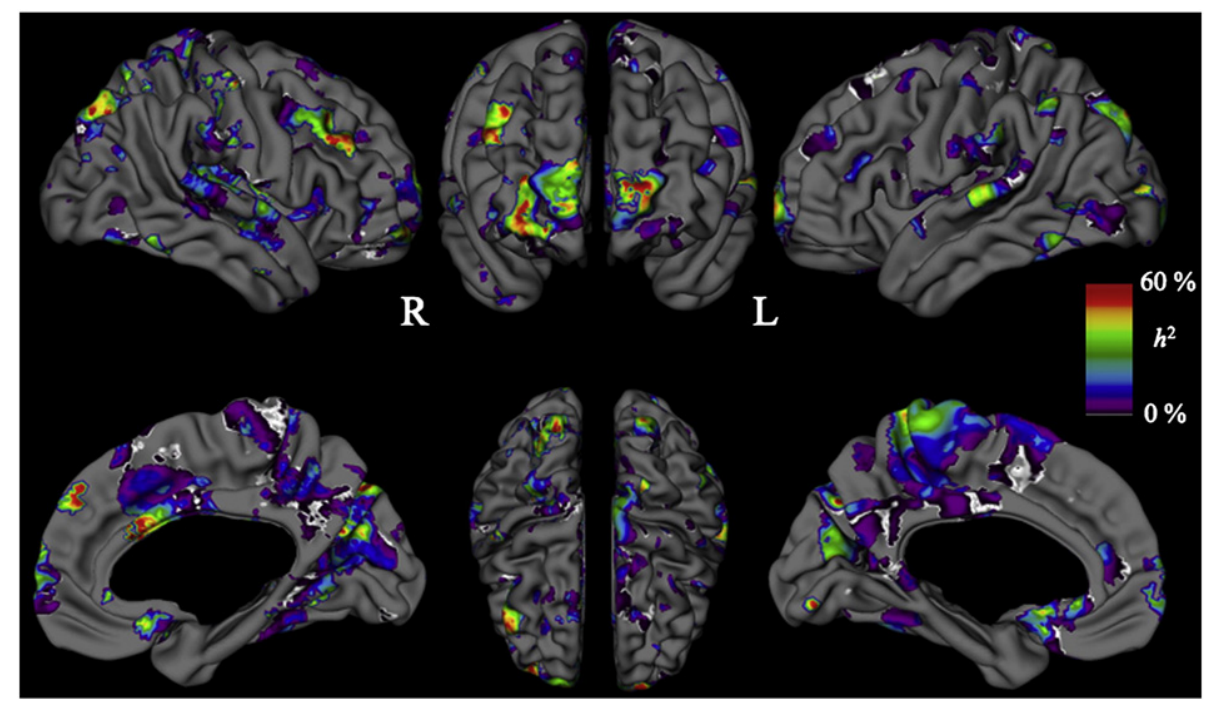

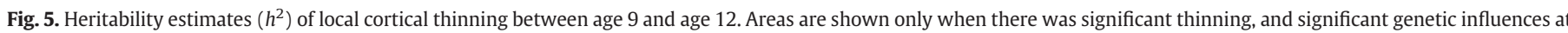
age 9 or at age 12 (FDR corrected) for left (L) and right (R) hemispheres, respectively. 


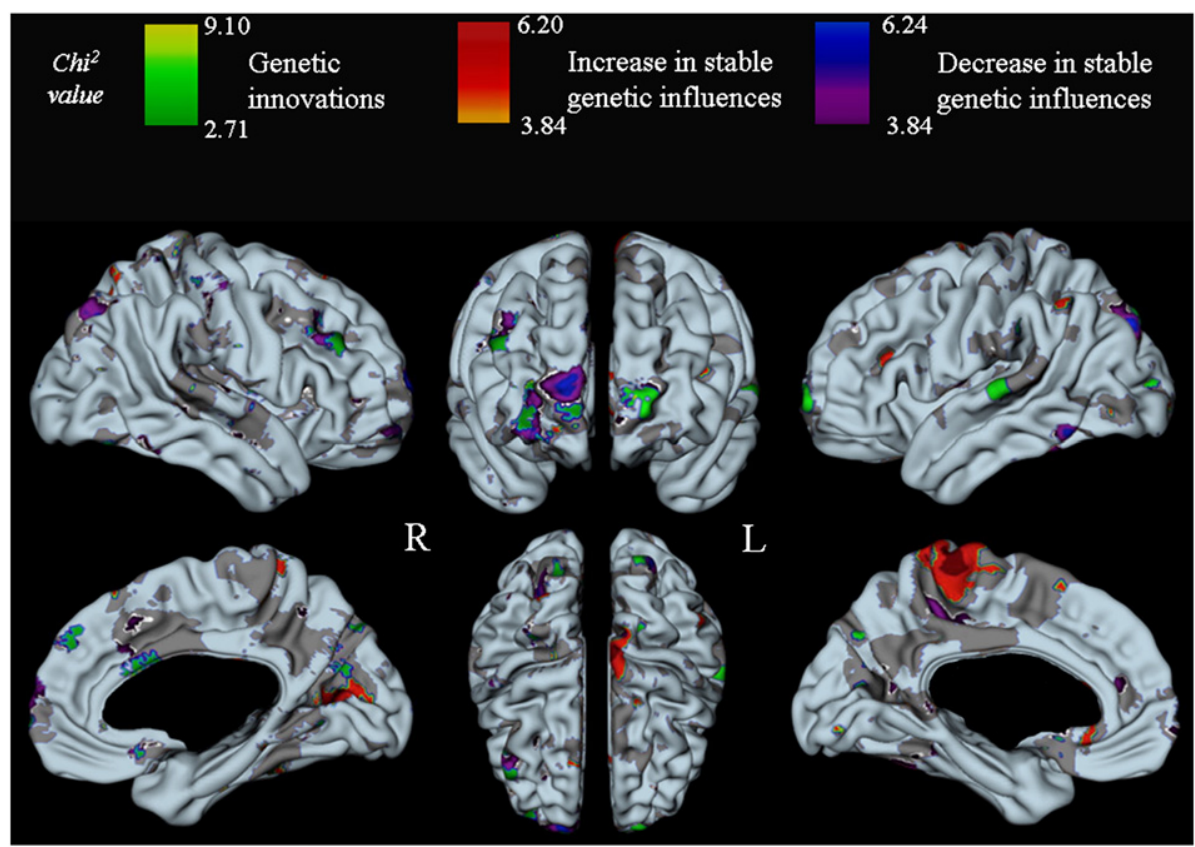

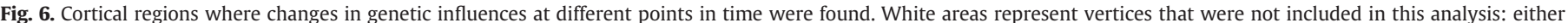

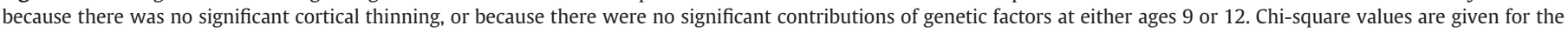

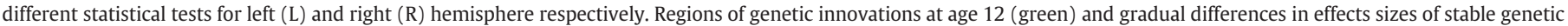
influences with age (blue and red).

\section{Discussion}

In this longitudinal MRI study a large group of twins were scanned at ages $9(\mathrm{~N}=190)$ and $12(\mathrm{~N}=125)$. A considerable thinning of $0.05 \mathrm{~mm}(1.5 \%)$ across the cerebral cortex was found in this threeyear interval. Cortical thinning was most pronounced in the frontal pole and orbito-frontal, sensory-motor and visual cortices during this period. We find this process to be highly heritable. Furthermore, genetic influences acting on the amount of change in cortical thickness were locally driven by independent genetic factors, both between brain regions, and across time.

Variation in thinning of the left inferior frontal (Broca's area) and left parietal (Wernicke's area) cortices was driven by the same genetic factor. This genetic factor was independent from the genetic factor influencing left anterior paracentral (sensory motor) cortical thinning. Cortical thinning in the left and right frontal poles is affected by two genetic factors: one factor of decreasing influence over time, and another independent genetic factor at age 12 in left and right frontal poles. Thus, developmental thinning of the cerebral cortex is heritable in children developing into adolescents. Different genetic factors are responsible for variation in cortical thickness at ages 9 and 12, and different genetic factors influence thickness across time and between various brain areas.

This is the first longitudinal study on genetic and environmental contributions to cortical gray matter changes during childhood. Because of the genetically informative longitudinal design, it was possible to explore how genetic mechanisms exert their effects on individual differences in cortical development. This study shows not only that cortical thinning is heritable in adolescence, as previously reported in adulthood (Brans et al., 2010), but that between

Table 2

Cortical regions where genetic innovation at age 12 was found.

\begin{tabular}{|c|c|c|c|c|c|c|c|c|c|c|}
\hline \multirow[b]{2}{*}{ Cortical area } & \multirow[b]{2}{*}{$\begin{array}{l}\text { MNI coordinates } \\
{[\mathrm{X}, \mathrm{Y}, \mathrm{Z}]}\end{array}$} & \multicolumn{2}{|c|}{ Baseline } & \multicolumn{2}{|c|}{ Follow-up } & \multicolumn{3}{|c|}{ Cortical thickness change } & \multirow[b]{2}{*}{$\chi^{2}$} & \multirow[b]{2}{*}{ p-Value } \\
\hline & & $h^{2}$ & $\begin{array}{l}\text { Var A/Var E } \\
\left(* 10^{-2} \mathrm{~mm}^{2}\right)\end{array}$ & $h^{2}$ & $\begin{array}{l}\text { Var A/Var E } \\
\left(* 10^{-2} \mathrm{~mm}^{2}\right)\end{array}$ & $\begin{array}{l}\text { Mean thinning } \\
(\mathrm{mm})\end{array}$ & $h^{2}$ & $\begin{array}{l}\text { Var A/Var E } \\
\left(* 10^{-2} \mathrm{~mm}^{2}\right)\end{array}$ & & \\
\hline Right medial prefrontal $^{a}$ & $32,58,-7$ & $44 \%$ & $2.96 / 3.82$ & $42 \%$ & $1.92 / 2.64$ & 0.10 & $55 \%$ & $2.72 / 2.23$ & 8.22 & .002 \\
\hline Right superior prefrontal & $14,69,-1$ & $45 \%$ & $6.57 / 7.95$ & $53 \%$ & $6.98 / 6.21$ & 0.19 & $50 \%$ & $6.61 / 6.61$ & 9.10 & .001 \\
\hline Right inferior prefrontal $^{a}$ & $26,55,-15$ & $45 \%$ & $6.05 / 4.49$ & $48 \%$ & $5.58 / 6.07$ & 0.06 & $55 \%$ & $6.35 / 5.20$ & 8.83 & .001 \\
\hline Right medial frontal $^{\mathrm{a}}$ & $48,34,26$ & $37 \%$ & $1.62 / 2.81$ & $39 \%$ & $1.56 / 2.45$ & 0.06 & $47 \%$ & $1.71 / 1.93$ & 5.40 & .020 \\
\hline Right superior frontal $^{\mathrm{a}}$ & $4,49,41$ & $35 \%$ & $2.96 / 5.41$ & $47 \%$ & $2.15 / 2.43$ & 0.03 & $78 \%$ & $3.35 / 0.94$ & 6.42 & $<.001$ \\
\hline Right subcallosal $^{\mathrm{a}}$ & $4,19,-16$ & $44 \%$ & $3.63 / 4.63$ & $40 \%$ & $2.35 / 3.52$ & 0.19 & $42 \%$ & $2.65 / 3.66$ & 5.37 & .010 \\
\hline Right cingulate & $3,24,22$ & $37 \%$ & $4.23 / 7.20$ & $55 \%$ & $6.11 / 4.94$ & 0.05 & $68 \%$ & $6.22 / 2.93$ & 6.56 & .005 \\
\hline Right cuneus & $3,-74,22$ & $48 \%$ & $2.01 / 2.21$ & $48 \%$ & $2.08 / 2.28$ & 0.10 & $51 \%$ & $0.88 / 0.85$ & 7.59 & .003 \\
\hline Right parieto-occipital $^{\mathrm{a}}$ & $19,-77,42$ & $45 \%$ & $1.74 / 2.11$ & $42 \%$ & $1.52 / 2.06$ & 0.06 & $56 \%$ & $1.55 / 1.22$ & 6.44 & .006 \\
\hline Left inferior prefrontal & $-19,68,0$ & $38 \%$ & $4.54 / 7.47$ & $45 \%$ & $5.43 / 6.60$ & 0.18 & $49 \%$ & $4.72 / 4.91$ & 8.32 & .002 \\
\hline Left superior temporal & $-63,-22,10$ & $44 \%$ & $2.18 / 2.80$ & $44 \%$ & $1.85 / 2.35$ & 0.08 & $48 \%$ & $1.24 / 1.34$ & 6.58 & .005 \\
\hline Left inferior parietal & $-19,-88,40$ & $50 \%$ & $2.35 / 2.33$ & $51 \%$ & $2.31 / 2.18$ & 0.10 & $51 \%$ & $2.17 / 2.08$ & 8.24 & .002 \\
\hline Left lateral occipital & $-26,-91,7$ & $34 \%$ & $2.87 / 5.48$ & $44 \%$ & $4.39 / 5.69$ & 0.15 & $46 \%$ & $5.42 / 6.36$ & 7.15 & .004 \\
\hline Left parieto-occipital & $-15,-74,36$ & $60 \%$ & $1.50 / 0.99$ & $54 \%$ & $1.36 / 1.14$ & 0.06 & $58 \%$ & $0.90 / 0.65$ & 7.44 & .003 \\
\hline
\end{tabular}

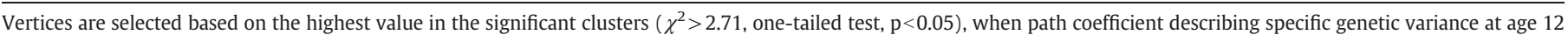

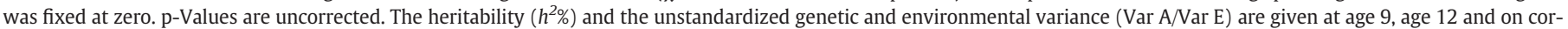
tical thinning.

${ }^{\text {a }}$ For these regions, additional significant gradual differences in effect size over time of the common genetic factor across time was found ( $\chi^{2}>3.84$, one-tailed test, $\mathrm{p}<0.05$ ) by constraining the paths $a_{11}$ and $a_{21}$ to be equal, while $a_{22}$ was freely estimated. 
Table 3

Cortical region with significant increase (A) or decrease (B) of stable genetic influences.

\begin{tabular}{|c|c|c|c|c|c|c|c|c|c|c|}
\hline \multirow[b]{2}{*}{ Cortical area } & \multirow[b]{2}{*}{$\begin{array}{l}\text { MNI coordinates } \\
{[\mathrm{X}, \mathrm{Y}, \mathrm{Z}]}\end{array}$} & \multicolumn{2}{|c|}{ Baseline } & \multicolumn{2}{|c|}{ Follow-up } & \multicolumn{3}{|c|}{ Cortical thickness change } & \multirow[b]{2}{*}{$\chi^{2}$} & \multirow[b]{2}{*}{ p-Value } \\
\hline & & $h^{2}$ & $\begin{array}{l}\text { Var A/Var E } \\
\left(* 10^{-2} \mathrm{~mm}^{2}\right)\end{array}$ & $h^{2}$ & $\begin{array}{l}\text { Var A/Var E } \\
\left(* 10^{-2} \mathrm{~mm}^{2}\right)\end{array}$ & $\begin{array}{l}\text { Mean thinning } \\
(\mathrm{mm})\end{array}$ & $h^{2}$ & $\begin{array}{l}\text { Var A/Var E } \\
\left(* 10^{-2} \mathrm{~mm}^{2}\right)\end{array}$ & & \\
\hline \multicolumn{11}{|c|}{ A. Increased influence of stable genetic factor } \\
\hline Right central & $11,-46,71$ & $13 \%$ & $0.96 / 6.24$ & $65 \%$ & $4.26 / 2.32$ & 0.08 & $19 \%$ & $1.17 / 4.99$ & 7.90 & .005 \\
\hline Right calcarine & $15,-74,12$ & $49 \%$ & $2.26 / 2.33$ & $76 \%$ & $4.36 / 1.39$ & 0.25 & $10 \%$ & $0.34 / 3.06$ & 7.26 & .007 \\
\hline Right inf isthmus & $22,-39,-12$ & $34 \%$ & $1.03 / 2.02$ & $60 \%$ & $1.91 / 1.29$ & 0.07 & $10 \%$ & $0.14 / 1.26$ & 10.61 & .001 \\
\hline Left anterior paracentral & $-2,-33,67$ & $30 \%$ & $2.08 / 4.79$ & $82 \%$ & $7.71 / 1.66$ & 0.09 & $34 \%$ & $1.78 / 3.14$ & 19.75 & $<.001$ \\
\hline Left inferior frontal & $-41,30,18$ & $10 \%$ & $0.30 / 2.79$ & $51 \%$ & $1.29 / 1.24$ & 0.06 & $15 \%$ & $0.34 / 1.93$ & 5.65 & .017 \\
\hline Left rostral cingulate & $-4,30,-7$ & $20 \%$ & $1.50 / 5.98$ & $66 \%$ & $4.36 / 2.23$ & 0.12 & $31 \%$ & $1.64 / 3.65$ & 6.48 & .011 \\
\hline Left inferior parietal & $-55,-51,45$ & $9 \%$ & $0.56 / 5.77$ & $59 \%$ & $3.51 / 2.47$ & 0.05 & $35 \%$ & $1.84 / 3.42$ & 8.18 & .004 \\
\hline Left central & $-12,-44,71$ & $31 \%$ & $1.38 / 3.07$ & $72 \%$ & $3.96 / 1.57$ & 0.08 & $43 \%$ & $1.32 / 1.75$ & 13.36 & $<.001$ \\
\hline \multicolumn{11}{|c|}{ B. Decreased influence of stable genetic factor } \\
\hline Right superior prefrontal & $12,66,11$ & $55 \%$ & $7.44 / 6.03$ & $.09 \%$ & $0.90 / 8.95$ & 0.12 & $42 \%$ & $5.23 / 7.22$ & 16.24 & $<.001$ \\
\hline Right medial prefrontal & $29,61,-9$ & $53 \%$ & $4.18 / 3.66$ & $24 \%$ & $1.64 / 5.14$ & 0.11 & $49 \%$ & $3.91 / 4.07$ & 12.50 & $<.001$ \\
\hline Right medial frontal & $39,26,41$ & $37 \%$ & $2.06 / 3.54$ & $27 \%$ & $1.01 / 2.70$ & 0.04 & $55 \%$ & $1.93 / 1.58$ & 9.41 & .002 \\
\hline Right inferior parietal & $29,-70,37$ & $52 \%$ & $1.92 / 1.80$ & $5 \%$ & $0.11 / 2.41$ & 0.08 & $49 \%$ & $1.10 / 1.14$ & 13.70 & $<.001$ \\
\hline Left cingulate sulcus & $-14,-42,48$ & $59 \%$ & $1.93 / 1.35$ & $22 \%$ & $0.68 / 2.41$ & 0.06 & $19 \%$ & $0.32 / 1.36$ & 10.39 & .001 \\
\hline Left anterior cingulate & $-13,41,16$ & $38 \%$ & $2.13 / 3.47$ & $9 \%$ & $0.42 / 4.04$ & 0.08 & $23 \%$ & $0.66 / 2.21$ & 6.51 & .011 \\
\hline Left frontal pole & $-18,64,9$ & $37 \%$ & $4.62 / 7.85$ & $26 \%$ & $2.65 / 7.50$ & 0.12 & $37 \%$ & $3.69 / 6.28$ & 5.99 & .014 \\
\hline Left inferior temporal & $-58,-56,-15$ & $53 \%$ & $4.11 / 3.58$ & $3 \%$ & $0.22 / 6.46$ & 0.06 & $37 \%$ & $2.43 / 4.14$ & 15.27 & $<.001$ \\
\hline Left inferior parietal & $-25,-84,37$ & $60 \%$ & $2.37 / 1.58$ & $0.04 \%$ & $0.14 / 3.50$ & 0.11 & $14 \%$ & $0.32 / 1.97$ & 15.56 & $<.001$ \\
\hline
\end{tabular}

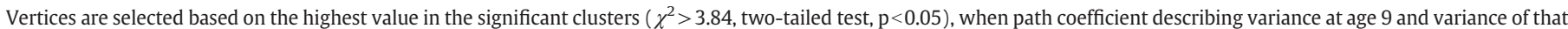

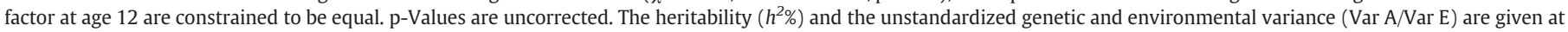
age 9 , age 12 and on cortical thinning.

ages 9 and 12 cortical thinning is driven by different genetic factors exerting their influence on particular areas of the cerebral cortex. That we find overall thinning between 9 and 12 years in this sample of children with an average IQ of 101 (van Soelen et al., 2011b) is consistent with earlier findings in a sample of children between 4 and 20 years where cortical thinning was also found to have started before age 12 (Shaw et al., 2006). It must be noted that the exact mechanism behind cortical thinning in adolescence is not known. Cortical thinning during puberty has been associated with the loss of unneeded connections (synaptic pruning; Huttenlocher and Dabholkar, 1997) but pruning cannot fully account for the observed thinning (Paus, 2005). Decrease in gray matter and the increase in

Table 4

Phenotypic and genetic correlations between regions of interest on cortical thickness changes.

\begin{tabular}{|c|c|c|c|c|}
\hline A. Genetic innovation & $\begin{array}{l}\text { MNI coordinates } \\
{[\mathrm{X}, \mathrm{Y}, \mathrm{Z}]}\end{array}$ & $\begin{array}{l}\text { L superior } \\
\text { temporal }\end{array}$ & $\mathrm{R}$ frontal & L frontal \\
\hline L superior temporal & $-63,-22,10$ & - & 0.00 & 0.22 \\
\hline $\mathrm{R}$ frontal & $14,69,-1$ & -0.01 & - & 0.50 \\
\hline L frontal & $-19,68,0$ & 0.55 & 0.83 & - \\
\hline $\begin{array}{l}\text { B. Increase in stable } \\
\text { genetic influences }\end{array}$ & $\begin{array}{l}\text { MNI coordinates } \\
{[\mathrm{X}, \mathrm{Y}, \mathrm{Z}]}\end{array}$ & $\begin{array}{l}\text { L inferior } \\
\text { frontal }\end{array}$ & $\begin{array}{l}\text { L inferior } \\
\text { parietal }\end{array}$ & $\begin{array}{l}\text { L anterior } \\
\text { paracentral } \\
\text { lobule }\end{array}$ \\
\hline L inferior frontal & $-41,30,18$ & - & 0.30 & 0.15 \\
\hline L inferior parietal & $-55,-51,45$ & 1.00 & - & 0.21 \\
\hline $\begin{array}{l}\text { L anterior paracentral } \\
\text { lobule }\end{array}$ & $-2,-33,67$ & -0.23 & -0.18 & - \\
\hline $\begin{array}{l}\text { C. Decrease in stable } \\
\text { genetic influences }\end{array}$ & & $\mathrm{R}$ frontal & $\begin{array}{l}\mathrm{R} \text { inferior } \\
\text { parietal }\end{array}$ & $\begin{array}{l}\text { L inferior } \\
\text { parietal }\end{array}$ \\
\hline $\mathrm{R}$ frontal & $12,66,11$ & - & 0.09 & 0.20 \\
\hline $\mathrm{R}$ inferior parietal & $29,-70,37$ & 0.12 & - & 0.28 \\
\hline $\mathrm{L}$ inferior parietal & $-25,-84,37$ & 0.34 & 0.18 & - \\
\hline
\end{tabular}

$\mathrm{L}=$ left side; $\mathrm{R}=$ right side; significant genetic correlations $(\mathrm{p}>0.05)$ are given in bold. Single vertices were selected within areas of genetic innovation at age 12 (A), increasing (B), and decreasing (C) stable genetic influences across time. Off diagonal above (italic) are the phenotypic correlations between the different regions and off diagonal below the genetic correlations are given. white matter are also thought to be a reflection of progressive agerelated axonal myelination (Benes et al., 1994; Yakovlev and Lecours, 1967), which is assumed to occur at the gray-white matter boundary (white matter encroachment; Gogtay and Thompson, 2010).

One other interesting finding is the suggestive evidence for waning influence of one genetic factor related to cortical thickness in the left and right frontal pole and the emerging activation of another genetic factor in the same regions (from 9 to 12 years). The frontal pole has been specifically associated with the evolution of the human species since it is one of the cortical areas of the frontal lobe that is enlarged in humans as compared to apes (Semendeferi et al., 2001). Furthermore, the frontal pole, or Brodmann Area 10, has also been associated with many cognitive functions, principally multitasking and dealing with novel situations (Dumontheil et al., 2008).

Bilateral thinning was considerable in the region on the top of the medial wall of the paracentral lobule in this 3-year period. An amplification of this stable genetic factor was found on the thickness of the primary sensory-motor cortex. This region has been found to be activated during genital stimulation, both in females (Michels et al., 2010) and in males (Kell et al., 2005). To which extent genes implicated in development of this primary sensory-motor in this period between ages 9 and 12 cortical area overlap with those implicated in the development of sexual hormones is of interest for future study.

The same genetic factor operates in language areas (e.g., left inferior frontal (superior of) Broca's and left parietal (superior of) Wernicke's area). In these areas amplification of the same genetic factors across ages 9 and 12 was observed. Between these two regions, the genetic factors acting on cortical thinning were completely overlapping and this might suggest that the genetic influences acting on cortical development in these areas are implicated in language.

We did not find significant influences of common environmental factors on cortical thickness. This is consistent with other neuroimaging studies in both adults (Peper et al., 2007), and children (Lenroot et al., 2009; Peper et al., 2009; Yoon et al., 2010) of both volumetric and cortical thickness measures. The narrow age range of our cohort makes it possible to assess genetic influences without age-related confounders, providing accurate heritability estimates at 9 and 12 years of age. The relatively 
A

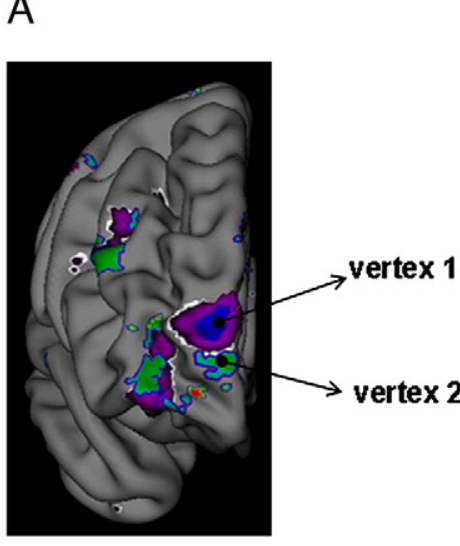

B

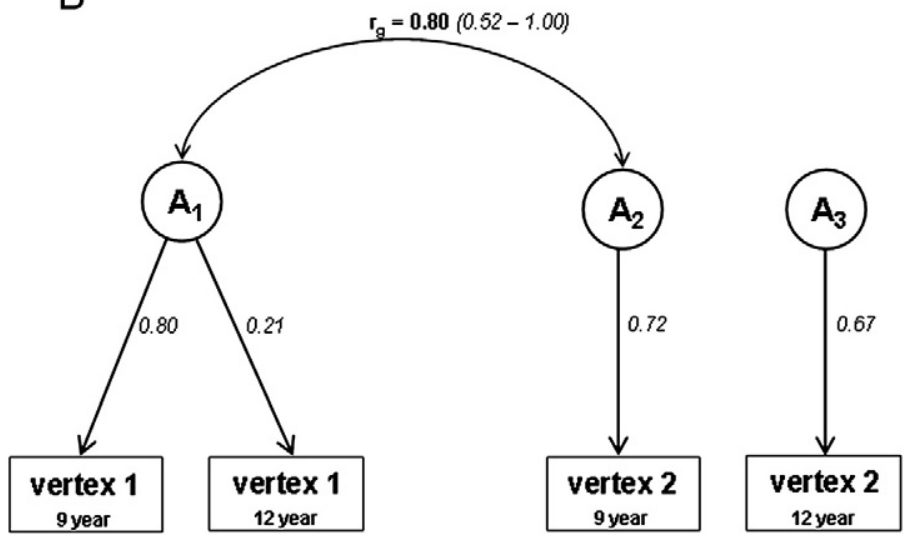

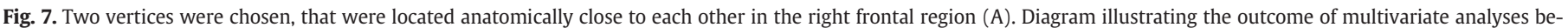

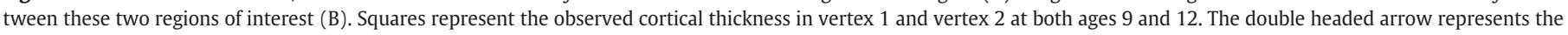

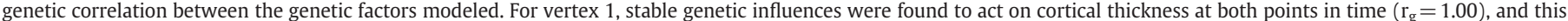

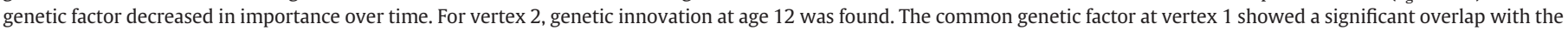
genetic factor at age 9 of vertex $2\left(r_{g}=0.80\right)$, and no significant overlap with the genetic factor at age 12 of vertex 2 .

high heritabilities for mean and local cortical thickness are consistent with one other study in children (Yoon et al., 2010), as well as with the impression that heritability increases with age (Lenroot et al., 2009).

In a large cross-sectional pediatric study with a wide age range of 5 up 19 years of age, it has been reported that regions that were functionally or anatomically connected with each other were more likely to be under control of the same genetic factors (Schmitt et al., 2008). Comparable conclusions were drawn in a large sample of middle aged twins (Rimol et al., 2010). In this study regional specific genetic influences acting on cortical thickness were found (Rimol et al., 2010). Results from our study now show that this phenomenon might also hold for genetic influences acting on the amount of thinning of the cortex.

There are a few limitations to take into consideration when interpreting the findings of this study. First, we did not identify specific genetic or environmental factors, and as a consequence did not model gene-environment correlation or gene by environment interactions. Gene-environment correlations describe the non-random distribution of genotypes over environments (or stated differently, genetic influences on a person's exposure to the environment). Gene by environment interaction describes the differential response to environmental exposure based on genotype. If gene-by-environment interaction is present, but not modeled it will result in increased estimates of unique environmental variance. If environmental influences are common to family members, the interaction will be absorbed into the genetic variance. Thus, one explanation for the lack of common environmental influences might be $\mathrm{G} \times \mathrm{C}$ interaction. The effects of GE correlation also depend on whether E consists of unique or common environmental influences: correlation between $\mathrm{G}$ and $\mathrm{C}$ acts like $\mathrm{C}$ (which we did not detect); correlation between $\mathrm{G}$ and $\mathrm{E}$ acts like $\mathrm{G}$ (Purcell, 2002) and thus could be included in the total heritability. Second, heritability estimates are based on local vertices and therefore dependent on local accuracy of the measurement. Third, when interpreting the findings of this study, we should keep in mind that the results are based on local vertices and therefore are dependent on local accuracy of the measurement. Finally, it is interesting to speculate which specific genes are represented by the genetic influences we found. There are examples of genes that are expressed throughout life and show a change in their expression pattern with maturation. For example, Brain-Derived Neurotrophic Factor (BDNF), is highly expressed in the cerebral cortex, and has an important role during brain development and in synaptic plasticity (Cohen-Cory et al., 2010). The expression pattern of BDNF was found to be unique for different anatomical regions, and coincides with maturation timing of different anatomical regions of the cortex (Webster et al., 2002, 2006;
Wong et al., 2009). Similar changes in expression levels in the prefrontal cortex were found for the expression of dopamine receptors (DAR1), $\mathrm{GABA}_{\mathrm{A}}$ receptor alpha-subunits, and Apolipoprotein-D (Duncan et al., 2010; Kim et al., 2009; Weickert et al., 2007). Thus, expression levels of genes can change during life and this could be one interpretation of the gradual changes or the upcoming different genetic factors between ages 9 and 12 that were observed.

\section{Conclusions}

This study shows the extent to which genetic factors can influence cortical changes during early puberty between 9 and 12 years of age. Importantly, we find both differences in the size of the contribution of stable genetic influences acting on cortical thickness, as well as evidence for independent genetic influences acting on cortical thickness at different ages. We interpret these findings as changes in gene expression patterns in various brain regions during cortical development in childhood. The complex interplay between genes, hormones and environment is important to fully understand how individual differences in healthy brain development arise. Understanding how genetic and environmental influences can act on normal brain development, can contribute to the understanding of the complex biological processes underlying healthy, but also disrupted brain development.

\section{Acknowledgments}

We thank the twins and their parents for making this study possible. This work was supported by the Netherlands Organization for Scientific Research (NWO 51.02 .060 (H.H.), 668.772 (D.B.); NWO-MagW 480-04-004 (D.B.); NWO/SPI 56-464-14192 (D.B.); NWO/Veni 451-10-007 (J.S.P.)), the European Research Council (ERC-230374) (DB), High Potential Grant Utrecht University (H.H.) and the support from the Neuroscience Campus Amsterdam (NCA).

\section{References}

Baare, W.F., Hulshoff Pol, H.E., Boomsma, D.I., Posthuma, D., de Geus, E.J., Schnack, H.G., van Haren, N.E., van Oel, C.J., Kahn, R.S., 2001. Quantitative genetic modeling of variation in human brain morphology. Cereb. Cortex 11, 816-824.

Benes, F.M., Turtle, M., Khan, Y., Farol, P., 1994. Myelination of a key relay zone in the hippocampal formation occurs in the human brain during childhood, adolescence, and adulthood. Arch. Gen. Psychiatry 51, 477-484.

Boomsma, D., Busjahn, A., Peltonen, L., 2002. Classical twin studies and beyond. Nat. Rev. Genet. 3, 872-882

Boomsma, D.I., de Geus, E.J., Vink, J.M., Stubbe, J.H., Distel, M.A., Hottenga, J.J., Posthuma, D., van Beijsterveldt, T.C., Hudziak, J.J., Bartels, M., Willemsen, G., 2006. Netherlands Twin Register: from twins to twin families. Twin Res. Hum. Genet. 9, 849-857. 
Brans, R.G., Kahn, R.S., Schnack, H.G., van Baal, G.C., Posthuma, D., van Haren, N.E., Lepage, C., Lerch, J.P., Collins, D.L., Evans, A.C., Boomsma, D.I., Hulshoff Pol, H.E., 2010. Brain plasticity and intellectual ability are influenced by shared genes. J. Neurosci. 30, 5519-5524.

Brouwer, R.M., Hulshoff Pol, H.E., Schnack, H.G., 2010. Segmentation of MRI brain scans using non-uniform partial volume densities. Neuroimage 49, 467-477.

Cohen-Cory, S., Kidane, A.H., Shirkey, N.J., Marshak, S., 2010. Brain-derived neurotrophic factor and the development of structural neuronal connectivity. Dev. Neurobiol. 70, 271-288.

Dominicus, A., Skrondal, A., Gjessing, H.K., Pedersen, N.L., Palmgren, J., 2006. Likelihood ratio tests in behavioral genetics: problems and solutions. Behav. Genet. 36, 331-340.

Dumontheil, I., Burgess, P.W., Blakemore, S.J., 2008. Development of rostral prefrontal cortex and cognitive and behavioural disorders. Dev. Med. Child Neurol. 50, 168-181.

Duncan, C.E., Webster, M.J., Rothmond, D.A., Bahn, S., Elashoff, M., Shannon, W.C., 2010. Prefrontal GABA(A) receptor alpha-subunit expression in normal postnatal human development and schizophrenia. J. Psychiatr. Res. 44, 673-681.

Durston, S., Nederveen, H., van Dijk, S., van Belle, J., de Zeeuw, P., Langen, M., van Dijk, A., 2009. Magnetic resonance simulation is effective in reducing anxiety related to magnetic resonance scanning in children. J. Am. Acad. Child Adolesc. Psychiatry 48, 206-207.

Falconer, D.S., Mackay, T.F.C., 1996. Introduction to Quantitative Genetics. Prentice Hall, London.

Genovese, C.R., Lazar, N.A., Nichols, T., 2002. Thresholding of statistical maps in functional neuroimaging using the false discovery rate. Neuroimage $15,870-878$.

Giedd, J.N., Blumenthal, J., Jeffries, N.O., Castellanos, F.X., Liu, H., Zijdenbos, A., Paus, T. Evans, A.C., Rapoport, J.L., 1999. Brain development during childhood and adolescence: a longitudinal MRI study. Nat. Neurosci. 2, 861-863.

Gogtay, N., Thompson, P.M., 2010. Mapping gray matter development: implications for typical development and vulnerability to psychopathology. Brain Cogn. 72, 6-15.

Gogtay, N., Giedd, J.N., Lusk, L., Hayashi, K.M., Greenstein, D., Vaituzis, A.C., Nugent, T.F. Herman, D.H., Clasen, L.S., Toga, A.W., Rapoport, J.L., Thompson, P.M., 2004. Dynamic mapping of human cortical development during childhood through early adulthood. Proc. Natl. Acad. Sci. U. S. A. 101, 8174-8179.

Huttenlocher, P.R., Dabholkar, A.S., 1997. Regional differences in synaptogenesis in human cerebral cortex. J. Comp. Neurol. 387, 167-178.

Kell, C.A., von, K.K., Rosler, A., Kleinschmidt, A., Laufs, H., 2005. The sensory cortical representation of the human penis: revisiting somatotopy in the male homunculus. J. Neurosci. 25, 5984-5987.

Kim, J.S., Singh, V., Lee, J.K., Lerch, J., Ad-Dab'bagh, Y., MacDonald, D., Lee, J.M., Kim, S.I. Evans, A.C., 2005. Automated 3-D extraction and evaluation of the inner and outer cortical surfaces using a Laplacian map and partial volume effect classification. Neuroimage 27, 210-221.

Kim, W.S., Wong, J., Weickert, C.S., Webster, M.J., Bahn, S., Garner, B., 2009. Apolipoprotein-D expression is increased during development and maturation of the human prefrontal cortex. J. Neurochem. 109, 1053-1066.

Kremen, W.S., Prom-Wormley, E., Panizzon, M.S., Eyler, L.T., Fischl, B., Neale, M.C., Franz, C.E., Lyons, M.J., Pacheco, J., Perry, M.E., Stevens, A., Schmitt, J.E., Grant, M.D., Seidman, L.J., Thermenos, H.W., Tsuang, M.T., Eisen, S.A., Dale, A.M., Fennema-Notestine, C., 2010. Genetic and environmental influences on the size of specific brain regions in midlife: the VETSA MRI study. Neuroimage 49, 1213-1223.

Lenroot, R.K., Schmitt, J.E., Ordaz, S.J., Wallace, G.L., Neale, M.C., Lerch, J.P., Kendler, K.S., Evans, A.C., Giedd, J.N., 2009. Differences in genetic and environmental influences on the human cerebral cortex associated with development during childhood and adolescence. Hum. Brain Mapp. 30, 163-174.

Lerch, J.P., Pruessner, J., Zijdenbos, A.P., Collins, D.L., Teipel, S.J., Hampel, H., Evans, A.C., 2008. Automated cortical thickness measurements from MRI can accurately separate Alzheimer's patients from normal elderly controls. Neurobiol. Aging 29, 23-30.

Lyttelton, O., Boucher, M., Robbins, S., Evans, A., 2007. An unbiased iterative group registration template for cortical surface analysis. Neuroimage 34, 1535-1544.

Michels, L., Mehnert, U., Boy, S., Schurch, B., Kollias, S., 2010. The somatosensory representation of the human clitoris: an fMRI study. Neuroimage 49, 177-184.

Neale, M.C., Boker, S.M., Xie, G., Maes, H.H., 2006. Mx: Statistical Modeling. Department of Psychiatry, VCU Box 900126, Richmond, VA 23298.

Oldfield, R.C., 1971. The assessment and analysis of handedness: the Edinburgh inventory. Neuropsychologia 9, 97-113.

Panizzon, M.S., Fennema-Notestine, C., Eyler, L.T., Jernigan, T.L., Prom-Wormley, E., Neale, M., Jacobson, K., Lyons, M.J., Grant, M.D., Franz, C.E., Xian, H., Tsuang, M., Fischl, B., Seidman, L., Dale, A., Kremen, W.S., 2009. Distinct genetic influences on cortical surface area and cortical thickness. Cereb. Cortex 19, 2728-2735.
Paus, T., 2005. Mapping brain maturation and cognitive development during adolescence. Trends Cogn. Sci. 9, 60-68.

Peper, J.S., Brouwer, R.M., Boomsma, D.I., Kahn, R.S., Hulshoff Pol, H.E., 2007. Genetic influences on human brain structure: a review of brain imaging studies in twins. Hum. Brain Mapp. 28, 464-473.

Peper, J.S., Brouwer, R.M., Schnack, H.G., van Baal, G.C., van, L.M., van den Berg, S.M., de Waal HA, Delemarre-van, Janke, A.L., Collins, D.L., Evans, A.C., Boomsma, D.I., Kahn, R.S., Hulshoff Pol, H.E., 2008. Cerebral white matter in early puberty is associated with luteinizing hormone concentrations. Psychoneuroendocrinology 33, 909-915.

Peper, J.S., Schnack, H.G., Brouwer, R.M., van Baal, G.C., Pjetri, E., Szekely, E., van, L.M., van den Berg, S.M., Collins, D.L., Evans, A.C., Boomsma, D.I., Kahn, R.S, Hulshoff Pol, H.E., 2009. Heritability of regional and global brain structure at the onset of puberty: a magnetic resonance imaging study in 9-year-old twin pairs. Hum. Brain Mapp. 30, 2184-2196.

Purcell, S., 2002. Variance components models for gene-environment interaction in twin analysis. Twin Res. 5, 554-571.

Rimol, L.M., Panizzon, M.S., Fennema-Notestine, C., Eyler, L.T., Fischl, B., Franz, C.E., Hagler, D.J., Lyons, M.J., Neale, M.C., Pacheco, J., Perry, M.E., Schmitt, J.E., Grant, M.D., Seidman, L.J., Thermenos, H.W., Tsuang, M.T., Eisen, S.A., Kremen, W.S. Dale, A.M., 2010. Cortical thickness is influenced by regionally specific genetic factors. Biol. Psychiatry 67, 493-499.

Schmitt, J.E., Eyler, L.T., Giedd, J.N., Kremen, W.S., Kendler, K.S., Neale, M.C., 2007a Review of twin and family studies on neuroanatomic phenotypes and typical neurodevelopment. Twin Res. Hum. Genet. 10, 683-694.

Schmitt, J.E., Wallace, G.L., Rosenthal, M.A., Molloy, E.A., Ordaz, S., Lenroot, R., Clasen, L.S., Blumenthal, J.D., Kendler, K.S., Neale, M.C., Giedd, J.N., 2007b. A multivariate analysis of neuroanatomic relationships in a genetically informative pediatric sample. Neuroimage 35, 70-82.

Semendeferi, K., Amstrong, E., Schleicher, A., Zilles, K., van Hoesen, G.W., 2001 Prefrontal cortex in humans and apes: a comparative study of area 10 . Am. J Phys. Anthropol. 114, 224-241.

Shaw, P., Greenstein, D., Lerch, J., Clasen, L., Lenroot, R., Gogtay, N., Evans, A., Rapoport J., Giedd, J., 2006. Intellectual ability and cortical development in children and adolescents. Nature 440, 676-679.

Sled, J.G., Zijdenbos, A.P., Evans, A.C., 1998. A nonparametric method for automatic correction of intensity nonuniformity in MRI data. IEEE Trans. Med. Imaging 17, 87-97.

Sowell, E.R., Trauner, D.A., Gamst, A., Jernigan, T.L., 2002. Development of cortical and subcortical brain structures in childhood and adolescence: a structural MR study. Dev. Med. Child Neurol. 44, 4-16.

van Leeuwen, M., van den Berg, S.M., Boomsma, D.I., 2008. A twin-family study of general IQ. Learning and Individual Differences 18, 76-88.

van Soelen, I.L.C., Brouwer, R.M., van Leeuwen, M., Kahn, R.S., Hulshoff Pol, H.E Boomsma, D.I., 2011a. Heritability of verbal and performance intelligence in a pediatric longitudinal sample. Twin Res. Hum. Genet. 14, 119-128.

van Soelen, I.L.C., Brouwer, R.M., van Baal, G.C.M., Schnack, H.G., Peper, J.S., Chen, L Kahn, R.S., Boomsma, D.I., Hulshoff Pol, H.E., 2011b. Heritability of volumetric brain changes and height in children entering puberty. Accepted for Publication: Human Brain Mapping. doi:10.1002/hbm.21468.

Wallace, G.L., Eric, S.J., Lenroot, R., Viding, E., Ordaz, S., Rosenthal, M.A., Molloy, E.A., Clasen, L.S., Kendler, K.S., Neale, M.C., Giedd, J.N., 2006. A pediatric twin study of brain morphometry. J. Child Psychol. Psychiatry 47, 987-993.

Webster, M.J., Weickert, C.S., Herman, M.M., Kleinman, J.E., 2002. BDNF mRNA expression during postnatal development, maturation and aging of the human prefrontal cortex. Developmental Brain Research 139, 139-150.

Webster, M.J., Herman, M.M., Kleinman, J.E., Weickert, C.S., 2006. BDNF and trkB mRNA expression in the hippocampus and temporal cortex during the human lifespan. Gene Expr. Patterns 6, 941-951.

Weickert, C.S., Webster, M.J., Gondipalli, P., Rothmond, D., Fatula, R.J., Herman, M.M. Kleinman, J.E., Akil, M., 2007. Postnatal alterations in dopaminergic markers in the human prefrontal cortex. Neuroscience 144, 1109-1119.

Wong, J., Webster, M.J., Cassano, H., Weickert, C.S., 2009. Changes in alternative brainderived neurotrophic factor transcript expression in the developing human prefrontal cortex. Eur. J. Neurosci. 29, 1311-1322.

Yakovlev, P.I., Lecours, A., 1967. The myelogenetic cycles of regional maturation of the brain. In: Minkowski, A. (Ed.), Regional Development of the Brain in Early Life Blackwell, Oxford, pp. 3-70.

Yoon, U., Fahim, C., Perusse, D., Evans, A.C., 2010. Lateralized genetic and environmental influences on human brain morphology of 8-year-old twins. Neuroimage 53, 1117-1125. 